\title{
Article \\ Application of a Liquid-Liquid Microextraction Method Based on a Natural Hydrophobic Deep Eutectic Solvent for the Extraction of Plastic Migrants from Kombuchas
}

\author{
Antonio V. Herrera-Herrera ${ }^{1,2, *} \mathbb{C}$, Ruth Rodríguez-Ramos ${ }^{1}$, Álvaro Santana-Mayor ${ }^{1}{ }^{(\mathbb{D}}$, \\ Bárbara Socas-Rodríguez ${ }^{1}\left([)\right.$ and Miguel Ángel Rodríguez-Delgado ${ }^{1, *}$ \\ 1 Departamento de Química, Unidad Departamental de Química Analítica, Facultad de Ciencias, \\ Universidad de La Laguna (ULL), Avenida Astrofísico Francisco Sánchez, s/n, \\ 38206 San Cristóbal de La Laguna, Spain; rrodrira@ull.edu.es (R.R.-R.); asantanm@ull.edu.es (Á.S.-M.); \\ bsocasro@ull.edu.es (B.S.-R.) \\ 2 Instituto Universitario de Bio-Orgánica Antonio González, Universidad de La Laguna (ULL), Avda. \\ Astrofísico Fco. Sánchez, 2, 38206 San Cristóbal de La Laguna, Spain \\ * Correspondence: avherrer@ull.edu.es (A.V.H.-H.); mrguez@ull.edu.es (M.Á.R.-D.)
}

Citation: Herrera-Herrera, A.V.; Rodríguez-Ramos, R.;

Santana-Mayor, Á.; Socas-Rodríguez,

B.; Rodríguez-Delgado, M.Á.

Application of a Liquid-Liquid

Microextraction Method Based on a

Natural Hydrophobic Deep Eutectic

Solvent for the Extraction of Plastic

Migrants from Kombuchas. Molecules 2022, 27, 178. https://doi.org/

$10.3390 /$ molecules 27010178

Academic Editor: Nuno Neng

Received: 15 November 2021

Accepted: 25 December 2021

Published: 28 December 2021

Publisher's Note: MDPI stays neutral with regard to jurisdictional claims in published maps and institutional affiliations.

Copyright: (C) 2021 by the authors. Licensee MDPI, Basel, Switzerland. This article is an open access article distributed under the terms and conditions of the Creative Commons Attribution (CC BY) license (https:// creativecommons.org/licenses/by/ $4.0 /)$

\begin{abstract}
A vortex-assisted liquid-liquid microextraction, based on a natural hydrophobic deep eutectic solvent made from the monoterpene thymol and octanoic fatty acid, was employed for the analysis of 11 phthalate esters and one adipate in kombucha (a tea-based fermented beverage). Separation and determination were performed using an ultra-high performance liquid chromatography (UHPLC) system coupled to a single quadrupole mass spectrometer. Confirmatory analyses were carried out through UHPLC tandem mass spectrometry. The full method was validated in terms of matrix effect, matrix-matched calibration, sensitivity, recovery, limits of detection and quantification and repeatability. Satisfactory determination coefficients for quadratic calibration curves $(\geq 0.9938)$, recovery values $(67-120 \%)$ and limits of detection $(0.07-5.45 \mu \mathrm{g} / \mathrm{L})$ were obtained. Analysis of $26 \mathrm{kombucha}$ samples reported concentrations for dibutyl phthalate and dimethyl phthalate in the range between the limit of quantification (LOQ) and $16.18 \pm 1.14 \mu \mathrm{g} / \mathrm{L}$, although these phthalates were also detected under the LOQ in some of the analyzed samples. Only one of the samples bottled in plastic containers (7) did not present residues while only five of the 19 samples in glass bottles contained any plasticizer. However, the highest concentration was found in a kombucha bottled in food-grade glass. This work represents the first application in which phthalates and adipates are analyzed in kombuchas.
\end{abstract}

Keywords: kombucha; liquid-liquid microextraction; deep eutectic solvent; green solvent; phthalate acid esters; liquid chromatography

\section{Introduction}

Green chemistry, also known as sustainable chemistry, aims to design chemical protocols and substances that eliminate (or reduce as much as possible) the generation of hazardous materials [1]. Chemical processes often use significant amounts of non-renewable solvents with high polluting power. Under the umbrella of green chemistry, different alternative solvents have been developed [2] to avoid the contamination caused by the traditional ones and their intrinsic toxicity. Among them, low transition temperature mixtures (LTTMs, solvents formed by combinations of compounds and characterized by a low transition temperature between the solid and liquid states) and room temperature ionic liquids (ILs) have gained increasing interest [3]. In this regard, deep eutectic solvents (DESs) have also been widely studied [4,5] due to their superior characteristics (in comparison to ILs). Their nature consists of at least one hydrogen bond donor and one hydrogen bond acceptor interacting through strong hydrogen bonds (although other forces, such as Van der Waals, halogen, alkyl-alkyl and dipole bonds, and other electrostatic interactions are 
also involved). The melting point of DESs is considerably lower than that of the individual components and lower than expected from the enthalpies of fusion. Strictly speaking, DESs are characterized by a particular molar ratio of the individual constituents. However, there are different mixtures with melting temperatures lower than expected, which are frequently included in this category (although some authors prefer the term "eutectic mixtures"). DESs are cheap, viscous, non-flammable, have low volatility and their synthesis is easy and scalable. In addition, their toxicity is limited and they have good biodegradability. An aspect that should be cautiously considered is their recyclability. Different methods have been tested, including anti-solvent addition, membrane filtration, solid-liquid extraction, liquid-liquid extraction, supercritical fluid extraction, distillation, crystallization, separation due to density differences, etc. [6] Although additional studies are required, most of these methods usually employ high amounts of additional solvents and energy (with the inherent high cost). This problem can be exacerbated in applications employing high volumes of DESs. In this regard, the so-called natural DESs (NaDESs), entirely prepared from natural components (e.g., organic acids, sugars, amino acids, choline derivatives or fats) can be considered aligned with Green Analytical Chemistry principles. Although the first DESs used had a hydrophilic character, the introduction of hydrophobic DESs (HDESs) [7] was a real revolution because of their compatibility with aqueous samples without the need for extra reagents. In fact, NaHDESs have proven to be an interesting alternative in different analytical applications [7-9]. It should be mentioned that, despite their inherent advantages, it has been proved $[10,11]$ that the toxicity of certain DESs is higher than the aqueous solutions of the constituents due to a disruption effect on cell walls.

Global connection and development have led to the spread of ethnic foods around the world. In addition to their particular organoleptic characteristics and the possibility of using them in the fight against famine, their alleged and assumed health benefits are often behind this expansion. In this regard, Kombucha (a probiotic fermented drink) is attributed with therapeutic effects including anti-inflammatory, anticancer, antihypertensive, antidiabetic, hepatoprotective, and antimicrobial properties [12]. Moreover, additional preventive benefits have also been reported, such as delayed aging, improvement of gastrointestinal and glandular functions, blood detoxification and positive cholesterolemic effects [12,13]. These effects, attributed to the presence of different bioactive compounds (e.g., catechins, essential oils, flavonoids, organic acids, phenolic compounds and tannins) and to the symbiotic colony of bacteria and yeasts (SCOBY), remain uncertain as they have not yet been confirmed in humans [12]. Kombucha is thought to have originally appeared in China between 200 and 300 BC. For centuries it was a well-known (and even religiously tinged) beverage in Asian countries and spread around the world via trade routes. In the last two decades, it has become very popular all over the world. In fact, the global market size exceeded \$2.6 billion in 2020 and the compound annual growth rate between 2021 and 2027 is estimated at over 17\% [14]. Although different definitions have been proposed, kombucha is generally identified as a beverage obtained by fermentation of black, green, or oolong tea (although other substrates, such as sugar beet molasses and sweetened herbal extracts of mint, thyme, rosemary and fennel have also been tested) and sugar using a SCOBY. The result is a slightly sweet and sour sparkling drink (similar to apple cider for short fermentation and with vinegary aromas for long fermentation). Although the production was initially a kind of artisanal activity, today there are different companies producing commercial kombuchas with different varieties of flavor and ingredients. It is worth mentioning that some health risks have also been reported, mainly associated with overconsumption, kombucha contaminated with metals, inorganic substances introduced during production, consumption of highly acidic samples and consumption by people with previous illnesses [12]. However, to the best of our knowledge, organic contaminants in kombucha have not been analyzed, despite the growing popularity of this beverage.

Plasticizers have become a major health concern due to their toxic effects. In this regard, phthalate acidic esters (PAEs) can cause alterations of different tissues (kidney, liver, thyroid, reproductive system) and even cancer [15]. Their use in the agri-food industry (food pack- 
aging and contact material during processing) is frequent due to the properties they confer to the final material: flexibility, durability, transparency and longevity [16]. However, these compounds are not chemically bonded to the polymeric matrix but penetrate into these chains increasing flexibility. Consequently, and considering their stability and persistence, they are likely to migrate into the final product. In fact, different biomonitoring surveys have detected PAEs residues in human tissues [15,17]. Therefore, hundreds of analytical protocols have been developed for the analysis of these compounds in foods [18]. In this regard, the use of DESs has promoted new sustainable protocols [8,9,19-21]. We have recently developed a NaHDES based on thymol (Th):octanoic acid (OctA) (molar ratio 2:1) for vortex-assisted liquid-liquid microextraction (VA-LLME) of PAEs from tonic water (bottled in plastic, glass and metal containers) and cold infusions [9]. For this purpose, factors affecting extraction efficiency (i.e., type and proportions of NaHDES components, sample $\mathrm{pH}$ and NaHDES volume) were optimized using a univariate protocol. The method was demonstrated to be precise and repeatable and yielded recovery in the range $71-124 \%$ and lowest calibration levels between 0.025 and $1.25 \mu \mathrm{g} / \mathrm{L}$. From a Green Analytical Chemistry point of view, the method was evaluated applying the Analytical Eco-Scale [22] reaching 66 points (acceptable greenness). This method seems to be a good alternative for the extraction of this type of compound in different beverages, after the corresponding validation. In this respect, commercial kombuchas are typically bottled in food-grade glass (often with plastic caps), stainless steel vessels, or plastic [12] and the analysis of PAEs on them should be of interest due to the increasing consumption of these probiotic beverages.

For all the above, the aim of this work is the evaluation of the content of 11 PAEs (benzylbutyl phthalate, BBP; di-2-n-butoxyethyl phthalate, DBEP; dibutyl phthalate, DBP; dicyclohexyl phthalate, DCHP; di-(2-ethylhexyl) phthalate, DEHP; diethyl phthalate, DEP; di(2methoxyethyl)phthalate, DMEP; dimethyl phthalate, DMP; di-n-octyl phthalate, DNOP; din-pentyl phthalate, DNPP; dipropyl phthalate, DPP) and one adipate (bis(2-ethylhexyl) adipate, DEHA) residues in commercial kombuchas using a VA-LLME based on the NaHDES Th:OctA (molar ratio 2:1). To the best of our knowledge, this is the first time that PAEs and DEHA are analyzed in kombuchas.

\section{Results and Discussion}

\subsection{UHPLC-MS and UHPLC-MS/MS Methods}

A group of 11 PAEs plus one adipate (DEHA) were selected as key compounds in this study. Different international regulatory standards have been established to restrict the presence of these compounds in foods/drinks. In this regard the European Union, via Commission Regulation No 10/2011, has set a specific migration limit of $0.3 \mathrm{mg} / \mathrm{kg}$ for DBP, $1.5 \mathrm{mg} / \mathrm{kg}$ for DEHP, $18 \mathrm{mg} / \mathrm{kg}$ for DEHA, $30 \mathrm{mg} / \mathrm{kg}$ for BBP and a default value of $60 \mathrm{mg} / \mathrm{kg}$ for those compounds without a specific limit from plastic materials in contact with food [23]. For its part, the US EPA has included some of the selected PAEs (BBP, DBP, DEHP, DNOP and DNPP) in the Phthalates Action Plan [24] to ensure a correct assessment of this type of compounds.

In order to guarantee a correct separation and determination of these molecules, and bearing in mind that a single quadrupole $(Q)$ analyzer was used, a UHPLC method previously optimized for a similar group of compounds [25] was selected (fully described in Section 3.2). The mass spectrometer (MS) was initially operated in the full scan mode (using the chromatographic separation) to select the most intense ion for quantification in the single ion monitoring (SIM) mode. Once the optimal conditions were established, the possible contribution to the signal of compounds with close retention times was evaluated and, in that case, new ions were selected. Dibutyl phthalate-3,4,5,6- $\mathrm{d}_{4}\left(\mathrm{DBP}-\mathrm{d}_{4}\right)$ was used as internal standard (IS) for DMP, DMEP, DEP, DPP, BBP, DBP, DBEP, DEHP, DNPP and DCHP $(\mathrm{Rt}<6.0 \mathrm{~min})$ and dihexyl phthalate-3,4,5,6- $\mathrm{d}_{4}\left(\mathrm{DHP}-\mathrm{d}_{4}\right)$ was employed for DEHA and DNOP (Rt $>6.0 \mathrm{~min}$ ) due to their similar behavior to those substances. Adequate separation was observed for the target analytes with a total analysis time of $11 \mathrm{~min}$. Figure 1 shows 
the chromatograms obtained under these conditions for the selected analytes injected at $150 \mu \mathrm{g} / \mathrm{L}$.

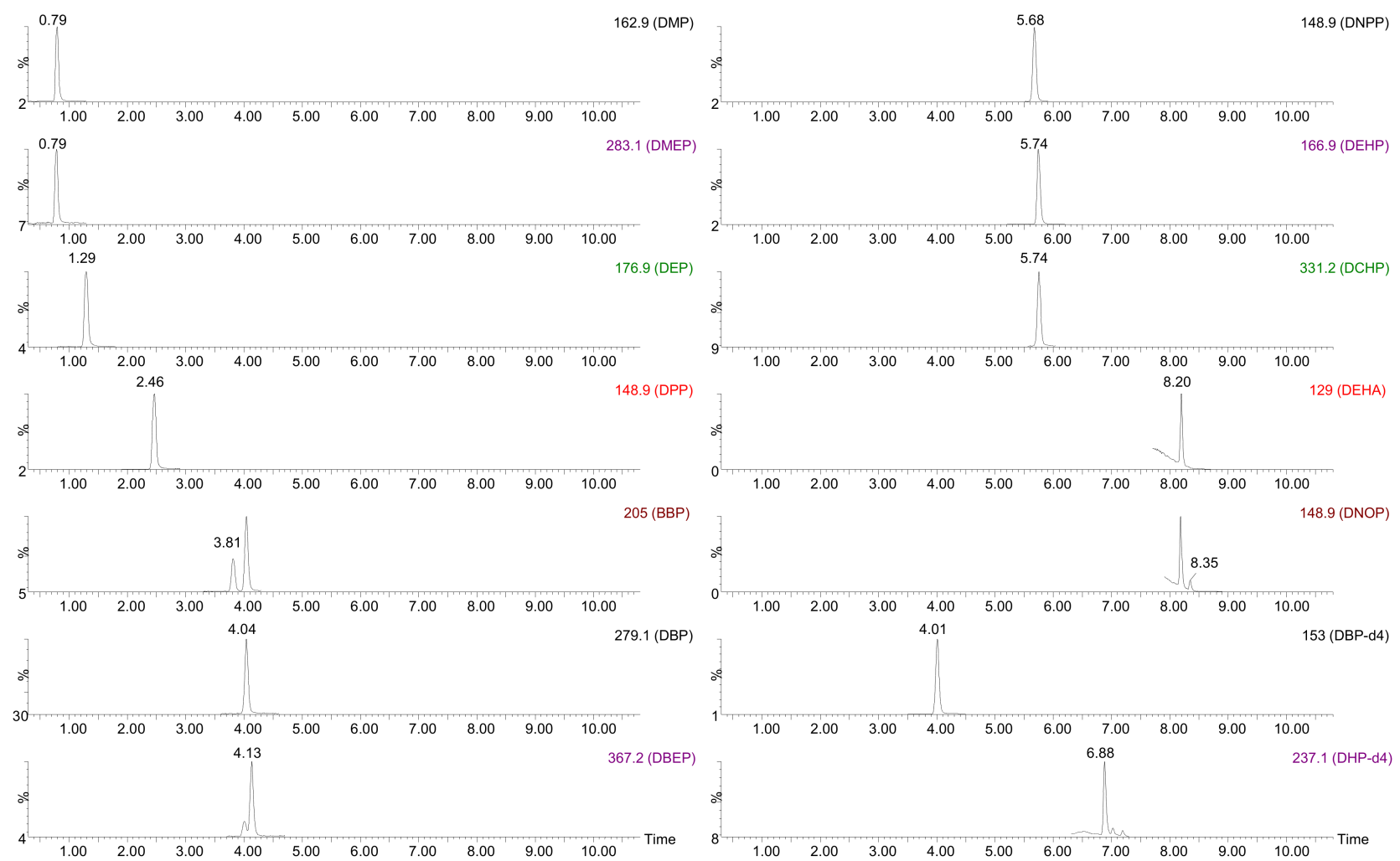

Figure 1. UHPLC-MS chromatogram for a mixture of standards at $150 \mu \mathrm{g} / \mathrm{L}$. Aqueous mobile phase: $0.1 \% v / v$ formic acid in Milli-Q water. Organic mobile phase: $0.1 \% v / v$ formic acid in acetonitrile. Flow: $0.3 \mathrm{~mL} / \mathrm{min}$. MS operated in SIM mode.

Since the objective of this work is to check the presence of PAEs residues in kombuchas, those samples presenting one of these compounds were also analyzed with a UHPLCMS/MS instrument using the conditions described by Santana-Mayor et al. [9]. Those conditions are included in Section 3.2. It should be noted that this confirmatory protocol allows ratification of the presence/absence of PAEs in less than $5.0 \mathrm{~min}$.

\subsection{VA-LLME of Kombuchas Using NaHDES}

The NaHDES Th:OctA 2:1 was previously employed in our laboratory [9] for the extraction of a similar group of PAEs from tonic water and cold infusion with good results. Therefore, it is a promising protocol for the analysis of other beverages. However, considering the complexity of kombuchas with regards to the previously analyzed drinks (with several different ingredients and SCOBY), the method must be fully validated. The samples were firstly centrifuged and filtered to separate the SCOBY. The omnipresent occurrence of PAEs in laboratory material, high-purity solvents and laboratory air dust difficult their analysis [26]. A frequently applied strategy [26] consists of extracting procedural blanks (matrix and Milli-Q water) in each analyzed batch and subtracting peak areas (when necessary) to avoid biased results.

The properties of NaHDESs composed of terpenes and monocarboxylic acids have been previously studied $[27,28]$. Martins et al. [27] found that DESs prepared from Th and monocarboxylic acids (including OctA) showed a higher hydrogen-bond acidity character than other typical organic solvents (alcohols ketones, alkanes and aromatics) but slightly lower than that of water. This behavior was almost independent of the alkyl chain length of the acid. Moreover, these NaHDESs presented a higher ability to establish non-specific 
interactions with solutes than other organic solvents due to the aromatic ring on Th, which also decreases its ability to act as a hydrogen bond acceptor. Thus, although other interactions cannot be ruled out, we hypothesize that the extraction is performed by the formation of $\pi-\pi$ interactions between PAEs and NaHDES. This is also in agreement with the fact that, in our previous application [9], better extraction efficiency was observed by using the Th:OctA molar ratio 2:1, since proportionately larger quantities of Th will increase the number of $\pi-\pi$ interactions.

\section{Validation of the Method}

The VA-LLME-UHPLC-MS (Q) method was validated in terms of matrix effect (ME), calibration, sensitivity, extraction efficiency, limits of detection and quantification, and repeatability.

The presence in the matrix of other compounds than analytes could result in an increase or decrease of the signal when chromatography coupled to MS is employed [29]. This fact could be particularly important in these complex samples due to the introduction of the NaHDES components in the final extract. Therefore, a ME study was performed using the method proposed by Matuszewski et al. [30]. For this purpose, the signal for the analytes injected in the matrix (obtained after the application of the extraction protocol) is compared with those signals for the analytes dissolved in a solvent at the same concentration. Signal enhancement is produced when this ratio is greater than $100 \%$ while values below $100 \%$ indicate signal suppression. This study was performed at $37.5 \mu \mathrm{g} / \mathrm{L}$. As shown in Table 1, an important ME was observed for all selected compounds (except IS DBP- $\mathrm{d}_{4}$, ME: $107 \%$ ). Only the adipate (DEHA) presented a signal enhancement whereas the rest of the compounds were affected by significant signal suppression (ME: 13-66\%). In view of these results, ME compensation is essential for correct quantification.

Matrix-matched calibration is often applied for ME compensation when a blank matrix is available [29]. Therefore, analytes dissolved in the matrix extract were injected in triplicate at 8 increasing concentrations and calibration curves (peak area/IS peak area vs. concentration) were obtained. The use of isotope-labeled ISs as surrogates improves the accuracy by compensating for variations during sample preparation. To check the best fit for the calibration curve (linear or quadratic) the Mandel's test was applied [31]. This test compares the residual standard deviations of linear and non-linear models by means of an $F$-test. For the calculation of $F$ experimental the degrees of freedom for the linear and non-linear models are also used [31]:

$$
F_{\text {exp }}=\frac{(n-2) S_{y / x, \text { lin }}^{2}-(n-3) S_{y / x, \text { cuad }}^{2}}{S_{y / x, \text { cuad }}^{2}}
$$

where $S_{y / x, l i n}$ and $S_{y / x, \text { cuad }}$ are the residual standard deviations for the linear and quadratic model (respectively) and $n$ is the number of levels of concentration. As can be seen in Table 1 , $F_{\text {exp }}(26.56-6885.32)>>F_{\text {tab }}(6.61$ for $\alpha=0.05$, numerator degrees of freedom $=1, n-3=5$ ). Thus, quadratic curve calibrations with adequate determination coefficients $\left(R^{2}\right)$, higher than 0.9938 , were obtained for the PAEs. The results of this matrix-matched calibration, including equation, ranges tested (sample concentration) and $R^{2}$ are also compiled in Table 1. According to the ISO 8466-2:2001 [32], the instrument sensitivity (e) for quadratic calibration curves can be defined as its first derivative (Table 1), and the sensitivity in the center of the working range (E) is the slope of the tangent to the calibration function in that point (Table 1).

To assess the extraction efficiency of the VA-LLME, a recovery study was carried out at two levels of concentration. Five aliquots of spiked kombucha were extracted and the peak areas were compared with those obtained for the PAEs spiked at the same level in a blank extract. Table 2 shows the results for this study including the concentration levels. Recovery values for the low level $(2.5 \mu \mathrm{g} / \mathrm{L}$, except for DMEP, BBP, DBP and DNOP: 
$18.75 \mu \mathrm{g} / \mathrm{L})$ were in the range $67-120 \%$ with RSDs between $2 \%$ and $19 \%$, while for the high concentration $(50 \mu \mathrm{g} / \mathrm{L})$ recovery ranged between 107 and 120\% (RSDs: 3-16\%)

The limits of detection (LODs) and quantification (LOQs) of the method were estimated as those concentrations providing a signal-to-noise ratio $(\mathrm{S} / \mathrm{N})$ equal to three or ten, respectively (Table 2). LODs varied in the range $0.07-5.45 \mu \mathrm{g} / \mathrm{L}$ while the LOQs varied from $0.24 \mu \mathrm{g} / \mathrm{L}$ for DNPP to $18.15 \mu \mathrm{g} / \mathrm{L}$ for DMEP.

The Commission Decision 2002/657/EC expresses repeatability as the coefficient of variation (\%) of fortified samples analyzed with the same method on identical test items in the same laboratory by the same operator using the same equipment. The repeatability study was accomplished through five parallel extractions at $50 \mu \mathrm{g} / \mathrm{L}$. Satisfactory RSDs were obtained (in the range between $3 \%$ and 10\%).

Validation results demonstrate the applicability of the method for the extraction of PAEs and one adipate from selected probiotic beverages.

Table 1. Matrix effect (ME), Mandel's test and matrix-matched calibration data (area/area IS vs. concentration) for the selected PAEs and DEHA.

\begin{tabular}{|c|c|c|c|c|c|c|c|}
\hline \multirow[b]{2}{*}{ Analyte } & \multirow[b]{2}{*}{$\begin{array}{c}\text { ME \% } \\
\text { (RSD, \%) }\end{array}$} & \multirow{2}{*}{$\begin{array}{c}\text { Mandel's Test } \\
F_{\text {exp }} *\end{array}$} & \multicolumn{5}{|c|}{ Calibration Data $(n=8)$} \\
\hline & & & $\begin{array}{c}\text { Range of } \\
\text { Concentration \# } \\
(\mu \mathrm{g} / \mathrm{L})\end{array}$ & Regression Equation & $\mathbf{R}^{2}$ & e & $\mathrm{E}\left(10^{-2}\right)$ \\
\hline $\mathrm{DMP}$ & $16(1)$ & 592.87 & $1.25-62.50$ & $\begin{array}{c}y=(1.52 \pm 0.16) \cdot 10^{-4} x^{2}+(4.23 \pm \\
1.02) \cdot 10^{-3} x+(2.11 \pm 1.13) \cdot 10^{-2}\end{array}$ & 0.9996 & $\begin{array}{c}3.03 \cdot 10^{-4} \mathrm{x}+ \\
4.23 \cdot 10^{-3}\end{array}$ & 1.05 \\
\hline DMEP & $13(17)$ & 6885.32 & $18.75-62.50$ & $\begin{array}{c}y=(5.02 \pm 1.33) \cdot 10^{-5} x^{2}-(2.63 \pm \\
1.08) \cdot 10^{-3} x+(4.95 \pm 1.97) \cdot 10^{-2}\end{array}$ & 0.9999 & $\begin{array}{l}1.00 \cdot 10^{-4} \mathrm{x} \\
-2.63 \cdot 10^{-3}\end{array}$ & 0.16 \\
\hline DEP & $39(7)$ & 90.01 & $6.25-62.50$ & $\begin{array}{c}y=(1.46 \pm 0.60) \cdot 10^{-4} x^{2}-(0.29 \pm \\
4.24) \cdot 10^{-3} x+(0.43 \pm 5.42) \cdot 10^{-2}\end{array}$ & 0.9981 & $\begin{array}{l}2.92 \cdot 10^{-4} \mathrm{x} \\
-2.85 \cdot 10^{-4}\end{array}$ & 0.82 \\
\hline DPP & $17(3)$ & 63.94 & $1.25-62.50$ & $\begin{array}{c}y=(2.71 \pm 0.87) \cdot 10^{-4} x^{2}+(3.30 \pm \\
5.59) \cdot 10^{-3} x+(3.98 \pm 6.16) \cdot 10^{-2}\end{array}$ & 0.9952 & $\begin{array}{c}5.42 \cdot 10^{-4} \mathrm{x}+ \\
3.30 \cdot 10^{-3}\end{array}$ & 1.46 \\
\hline $\mathrm{BBP}$ & $19(1)$ & 71.67 & $12.50-62.50$ & $\begin{array}{c}\mathrm{y}=(8.56 \pm 6.11) \cdot 10^{-6} \mathrm{x}^{2}+(2.66 \pm \\
4.75) \cdot 10^{-4} x-(0.75 \pm 7.41) \cdot 10^{-3}\end{array}$ & 0.9991 & $\begin{array}{c}1.71 \cdot 10^{-5} \mathrm{x}+ \\
2.66 \cdot 10^{-4}\end{array}$ & 0.08 \\
\hline DBP & $17(5)$ & 43.41 & $18.75-62.50$ & $\begin{array}{c}y=(0.90 \pm 1.04) \cdot 10^{-4} x^{2}+(0.20 \pm \\
8.69) \cdot 10^{-3} x+(0.20 \pm 1.53) \cdot 10^{-1}\end{array}$ & 0.9999 & $\begin{array}{c}1.81 \cdot 10^{-4} \mathrm{x}+ \\
1.96 \cdot 10^{-4}\end{array}$ & 0.54 \\
\hline DBEP & $18(4)$ & 67.62 & $2.50-62.50$ & $\begin{array}{c}\mathrm{y}=(1.76 \pm 0.65) \cdot 10^{-5} \mathrm{x}^{2}+(1.22 \pm \\
4.36) \cdot 10^{-4} \mathrm{x}+(2.49 \pm 5.30) \cdot 10^{-3}\end{array}$ & 0.9957 & $\begin{array}{c}3.51 \cdot 10^{-5} \mathrm{x}+ \\
1.22 \cdot 10^{-4}\end{array}$ & 0.10 \\
\hline DNPP & $23(4)$ & 296.54 & $1.25-62.50$ & $\begin{array}{c}y=(3.38 \pm 0.51) \cdot 10^{-4} x^{2}+(4.17 \pm \\
3.24) \cdot 10^{-3} x+(3.89 \pm 3.57) \cdot 10^{-2}\end{array}$ & 0.9990 & $\begin{array}{c}6.77 \cdot 10^{-4} \mathrm{x}+ \\
4.17 \cdot 10^{-3}\end{array}$ & 1.82 \\
\hline DEHP & $15(3)$ & 123.52 & $1.25-62.50$ & $\begin{array}{c}y=(9.04 \pm 2.09) \cdot 10^{-5} x^{2}+(1.41 \pm \\
1.34) \cdot 10^{-3} x+(0.98 \pm 1.48) \cdot 10^{-2}\end{array}$ & 0.9977 & $\begin{array}{c}1.81 \cdot 10^{-4} \mathrm{x}+ \\
1.41 \cdot 10^{-3}\end{array}$ & 0.52 \\
\hline $\mathrm{DCHP}$ & $15(16)$ & 60.28 & $1.25-62.50$ & $\begin{array}{c}y=(6.71 \pm 2.22) \cdot 10^{-6} x^{2}+(0.30 \pm \\
1.42) \cdot 10^{-4} x+(2.38 \pm 1.57) \cdot 10^{-3}\end{array}$ & 0.9938 & $\begin{array}{c}1.34 \cdot 10^{-5} \mathrm{x}+ \\
3.01 \cdot 10^{-5}\end{array}$ & 0.03 \\
\hline DEHA & $245(2)$ & 171.98 & $1.25-62.50$ & $\begin{array}{c}y=(1.79 \pm 0.35) \cdot 10^{-4} x^{2}+(1.15 \pm \\
0.23) \cdot 10^{-2} x+(1.76 \pm 0.25) \cdot 10^{-1}\end{array}$ & 0.9994 & $\begin{array}{c}3.58 \cdot 10^{-4} \mathrm{x}+ \\
1.15 \cdot 10^{-2}\end{array}$ & 1.89 \\
\hline DNOP & $66(9)$ & 26.56 & $12.75-62.50$ & $\begin{array}{c}\mathrm{y}=(2.03 \pm 2.35) \cdot 10^{-4} \mathrm{x}^{2}+(1.30 \pm \\
1.83) \cdot 10^{-2} \mathrm{x}-(1.81 \pm 2.85) \cdot 10^{-1}\end{array}$ & 0.9985 & $\begin{array}{c}4.05 \cdot 10^{-4} \mathrm{x}+ \\
1.30 \cdot 10^{-2}\end{array}$ & 2.57 \\
\hline
\end{tabular}

\footnotetext{
${ }^{*} F_{\text {tab }(\alpha=0 \cdot 05,1, n-3=8)}=6.61$; ${ }^{\#}$ sample concentration.
} 
Table 2. Recovery values $(n=5)$, repeatability $(n=5)$ and LODs and LOQs of the VA-LLME-UHPLCMS method in kombuchas.

\begin{tabular}{|c|c|c|c|c|c|c|c|c|}
\hline \multirow[b]{2}{*}{ Analyte } & \multicolumn{4}{|c|}{ Recovery Study ( $n=5)$} & \multicolumn{2}{|c|}{ Repeatability $(n=5)$} & \multirow[b]{2}{*}{$\operatorname{LOD}(\mu \mathrm{g} / \mathrm{L})$} & \multirow[b]{2}{*}{ LOQ $(\mu \mathrm{g} / \mathrm{L})$} \\
\hline & $\begin{array}{c}\text { Concentration } \\
(\mu g / L)\end{array}$ & $\begin{array}{l}\text { Recovery, \% } \\
\text { (RSD, \%) }\end{array}$ & $\begin{array}{c}\text { Concentration } \\
(\mu \mathrm{g} / \mathrm{L})\end{array}$ & $\begin{array}{l}\text { Recovery, \% } \\
\text { (RSD, \%) }\end{array}$ & $\begin{array}{c}\text { Concentration } \\
(\mu \mathrm{g} / \mathrm{L})\end{array}$ & RSD, \% & & \\
\hline DMP & 2.5 & $100(6)$ & 50 & $110(3)$ & 50 & 7 & 0.21 & 0.70 \\
\hline DMEP & 18.75 & $117(2)$ & 50 & $116(3)$ & 50 & 4 & 5.45 & 18.15 \\
\hline DEP & 2.5 & $112(8)$ & 50 & $118(3)$ & 50 & 6 & 1.84 & 6.14 \\
\hline DPP & 2.5 & $115(6)$ & 50 & $120(6)$ & 50 & 4 & 0.12 & 0.40 \\
\hline BBP & 18.75 & $113(9)$ & 50 & $114(15)$ & 50 & 4 & 3.02 & 10.08 \\
\hline DBP & 18.75 & $120(4)$ & 50 & $113(12)$ & 50 & 2 & 2.93 & 9.77 \\
\hline DBEP & 2.5 & $119(11)$ & 50 & $112(14)$ & 50 & 3 & 0.61 & 2.04 \\
\hline DNPP & 18.75 & $96(13)$ & 50 & $115(12)$ & 50 & 10 & 0.07 & 0.24 \\
\hline DEHP & 2.5 & $110(19)$ & 50 & $115(9)$ & 50 & 9 & 0.09 & 0.29 \\
\hline DCHP & 2.5 & $67(16)$ & 50 & $117(11)$ & 50 & 6 & 0.26 & 0.86 \\
\hline DEHA & 2.5 & $99(19)$ & 50 & $114(13)$ & 50 & 5 & 0.25 & 0.82 \\
\hline DNOP & 18.75 & $107(7)$ & 50 & 107 (16) & 50 & 3 & 3.31 & 11.04 \\
\hline
\end{tabular}

\subsection{Occurrence of Plasticizers in Commercial Kombuchas}

Once the methodology was validated, a group of 26 samples was analyzed using the VA-LLME-UHPLC-MS method to determine the residues of PAEs and DEHA present in kombuchas marketed in the Canary Islands (Table 3). Among them, 19 samples were stored in glass bottles with plastic caps and seven in plastic containers. Two of the samples bottled in plastic were zero sugar (Table S1). It should be noted that all the samples had the EU organic product label since all the ingredients come from ecological agriculture.

Table 3. Results of the analysis of kombucha samples using the NaHDES-VA-LLME-UHPLCMS/MS method.

\begin{tabular}{ccc}
\hline \multirow{2}{*}{ Sample } & \multicolumn{2}{c}{ Analite Concentration $(\mu \mathrm{g} / \mathrm{L})(n=5)$} \\
\cline { 2 - 3 } & DMP & DBP \\
\hline K2 & $16.18 \pm 1.14$ & - \\
\hline K4 & $<$ LOQ & - \\
\hline K9 & $3.22 \pm 2.24$ & - \\
\hline K10 & $3.55 \pm 2.17$ & - \\
\hline K15 & $4.11 \pm 2.34$ & $<$ LOQ \\
\hline K20 & $<$ LOQ & $<$ LOQ \\
\hline K21 & - & $<$ LOQ \\
\hline K22 & $<$ LOQ & $<$ LOQ \\
\hline K23 & $<$ LOQ & $<$ LOQ \\
\hline K24 & $7.68 \pm 1.56$ & $<$ LOQ \\
\hline K25 & $<$ LOQ &
\end{tabular}

For those samples in which peaks were detected in the SIM mode at the retention times corresponding to the analytes, a t-test was applied in order to check whether the areas were statistically and significantly different from those of the blanks analyzed in the same batch. For peaks with areas that were different, the presence was confirmed by UHPLC-MS/MS. Only analytes with areas that were significantly distinct and confirmed by the presence of the two transitions and the established relative intensities between precursor and product ions in them, were quantified using the matrix-matched calibration. As mentioned above, peak areas for blanks were subtracted when necessary. The results of these analyses are 
shown in Table 3. The expanded uncertainty was calculated according to ISO standard 8466-2:2001 [32]. Five replicates were analyzed for each sample.

As can be seen, more than half of the samples did not contain any of the analyzed PAEs or DEHA. However, 11 samples contained at least one of the tested plasticizers. In this regard, only DMP and DBP could be found in the selected kombuchas. As expected, almost all kombuchas bottled in plastic (except K26) presented some of these compounds. However, the concentration was below the LOQ for the vast majority of these samples. Only sample K24 (brand I, original flavor) contained a PAE at a quantifiable concentration (DMP: $7.68 \pm 1.56 \mu \mathrm{g} / \mathrm{L}$ ). In contrast, only five of 19 kombuchas bottled in glass containers had any residue, but DMP was quantifiable in four of them and the highest concentration detected corresponded to one of these samples: K2, $16.18 \pm 1.14 \mu \mathrm{g} / \mathrm{L} ; \mathrm{K} 9,3.22 \pm 2.24 \mu \mathrm{g} / \mathrm{L} ; \mathrm{K} 10$, $3.55 \pm 2.17 \mu \mathrm{g} / \mathrm{L} ; \mathrm{K} 15,4.11 \pm 2.34 \mu \mathrm{g} / \mathrm{L}$. These results demonstrate that it is essential to monitor foods/drinks in which that substance is not expected to be found since PAEs can be introduced during the production step or even by the caps. The manufacturing line (home or industrial scale) may be composed of different plastic materials that can be transferred to the final kombuchas due to production conditions (boiling of tea leaves, fermentation at acidic $\mathrm{pH}$ for several days, automatic bottling, etc.). Moreover, another aspect that should be considered is storage. Some of the producers clearly indicated that their products must be stored between 2 and $4{ }^{\circ} \mathrm{C}$, but others did not. Some of the samples were stockpiled in freezers at shops but not all of them. Therefore, other factors that can favor the transference of PAES from bottles or caps, such as temperature, light and time since packaging, should be contemplated. Further studies in this direction would complement the findings and allow a more specific explanation.

In 2007 Bošnir et al. [33] conducted a study about the migration of PAES from plastic materials to mineral waters and soft drinks. They found that sample $\mathrm{pH}$ and preservatives had an important influence on migration rate. Regarding $\mathrm{pH}$ (since kombuchas have no declared preservatives), acidity media increased the migration of PAEs. Among the studied compounds (DMP, DBP, DEP, BBP and DEHP), DMP (followed by DBP and DEHP) presented the higher migration rates in soft drinks $(\mathrm{pH}<3)$. This effect can explain the higher concentrations of DMP and DBP in the studied samples ( $\mathrm{pH}$ for kombuchas: 2.80-3.25).

It should be mentioned that no residues of DEHA and DEHP were found (both with restricted limits regulated by the US EPA [34] and WHO [35] in drinking waters. The use of DEHA as an alternative to DEHP is becoming increasingly popular in food contact films and PVC plastics [36]. In addition, its high migration potential [37] and its similar metabolism to DEHP (although more lipophilic), make this compound one of the more hazardous plasticizers. The absence of this compound is good news from a food security perspective. DBP, which migration limit is $0.3 \mathrm{mg} / \mathrm{kg}$ in the Commission Regulation No $10 / 2011$ on plastic materials and articles intended to come into contact with food, was detected in five plastic bottles at a concentration lower than LOQ. Figure 2 shows the UHPLC-MS/MS confirmation chromatogram for DMP in sample K2.

Although, as mentioned, there are no previous publications analyzing PAES in kombuchas, since these fermented beverages are prepared from sweetened tea extracts, parallelism can be established with tea drinks (other popular non-alcoholic beverages). In this regard, Wu et al. [38] analyzed 12 tea drinks (sport drinks, coffee drinks and fruit juices were also analyzed) and detected DMP in the range $<$ LOQ-19 $\mu \mathrm{g} / \mathrm{L}$, DEP: $<\mathrm{LOQ}-$ $76 \mu \mathrm{g} / \mathrm{L}$, DPP: <LOQ-71 $\mu \mathrm{g} / \mathrm{L}$, DBP: <LOQ; BBP: <LOQ-29 $\mu \mathrm{g} / \mathrm{L}$, and DEHP: 16-123 $\mu \mathrm{g} / \mathrm{L}$. Xue et al. [39] analyzed 105 samples of six different types of drinks and detected DMP: $<\mathrm{LOQ}-1.30 \mu \mathrm{g} / \mathrm{L}, \mathrm{DEP}:<\mathrm{LOQ}-0.11 \mu \mathrm{g} / \mathrm{L}, \mathrm{DBP}:<\mathrm{LOQ}-3.60 \mu \mathrm{g} / \mathrm{L}, \mathrm{BBP}:<\mathrm{LOQ}-0.19 \mu \mathrm{g} / \mathrm{L}$, and DEHP: $0.5-12.00 \mu \mathrm{g} / \mathrm{L}$ in tea drinks (22 samples). They also tested the influence of packaging materials (plastic, glass, metal and paper) on the PAEs concentration. Contrary to their expectations (and similar to our results), beverages bottled in paper contained the highest summed concentration of the analyzed PAEs, followed by those bottled in glass, metal and plastic drinks. Apart from a non-representative number of samples for the inves- 
tigation of the effect of packaging material, the authors explained their results on the basis of the different materials used by different vendors for the same type of plastic package. Also, we detected DEHP in tea drinks in a previous application, but at a concentration below the LOQ [19]. Kombucha samples contained a lower number of PAEs than analyzed tea drinks. Moreover, found concentrations ( $<\mathrm{LOQ}-16.18 \pm 1.14 \mu \mathrm{g} / \mathrm{L})$ were similar [39] or even lower [38] than those found for other tea-based beverages.

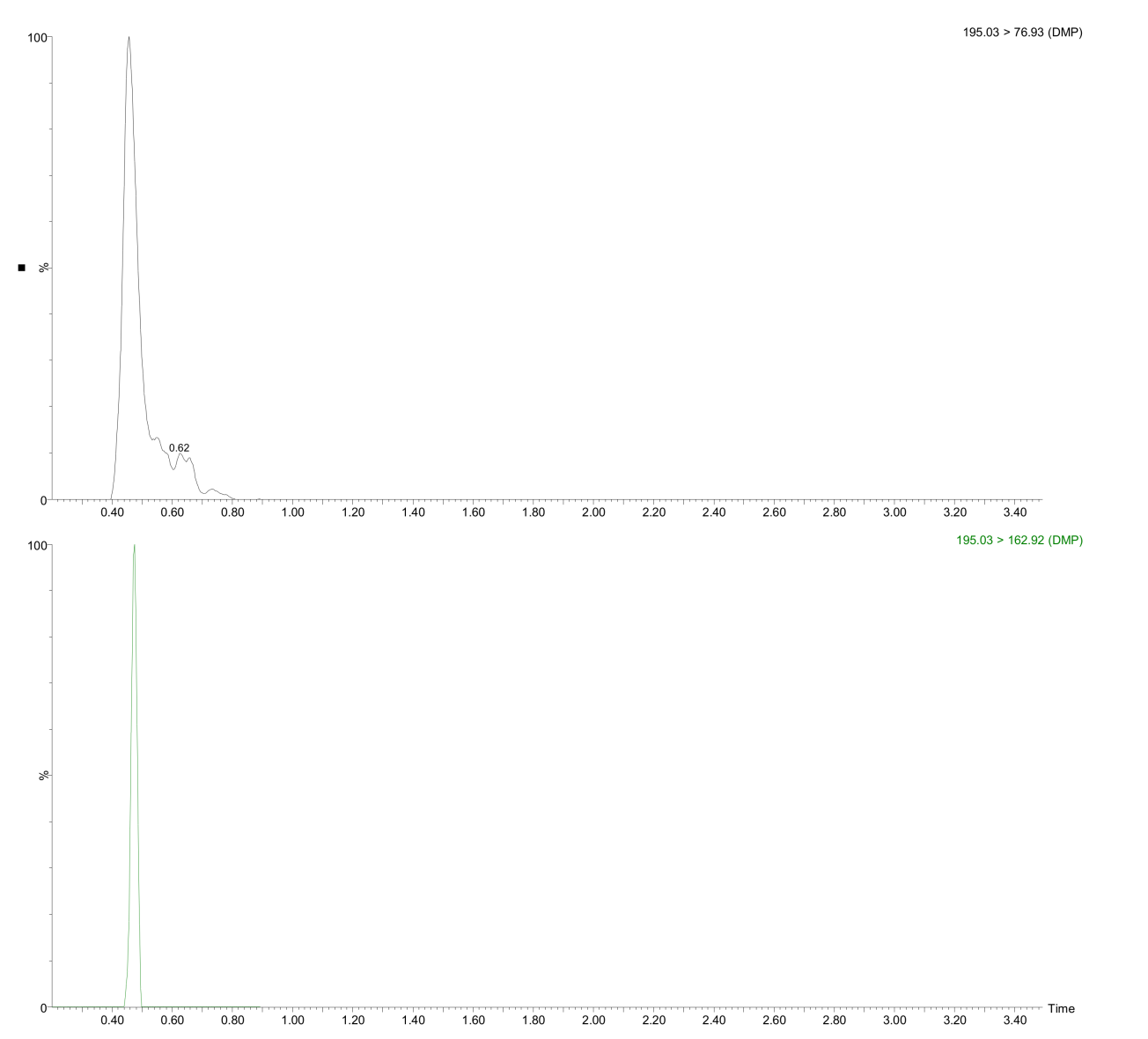

Figure 2. UHPLC-MS/MS chromatogram for detected analyte (DMP) in sample K2 submitted to the developed extraction procedure.

In order to provide an idea of the exposure to DMP (the only quantifiable PAE in these samples) due to the ingestion of kombuchas, the estimated daily intake was calculated through the following equation [40]:

$$
E D I=\frac{C \cdot Q}{b w} r_{\text {uptake }}
$$

where $E D I(\mu \mathrm{g} / \mathrm{kg}-\mathrm{bw} / \mathrm{d})$ is the estimated intake, $C$ is the phthalate concentration in the food, $Q$ is the average daily ingestion of this food, $b w$ is the body weight and $r_{\text {uptake }}$ is the gastrointestinal absorption factor. The European Food Safety Authority [41] and the WHO [42] recommend a daily water intake between 2 and $4 \mathrm{~L} \mathrm{(80 \%} \mathrm{from} \mathrm{beverages} \mathrm{and} \mathrm{20 \%}$ from water in foods [41]). For the calculation, the maximum intake for beverages ( $80 \%$ of $4 \mathrm{~L}$ ) is considered to come from kombucha. Considering the average concentration of DMP in the samples $(6.95 \mu \mathrm{g} / \mathrm{L})$ and a global average adult weight of $62 \mathrm{~kg}$ [43] and assuming a total absorption $\left(r_{\text {uptake }}=1\right)$, the maximum EDI for DMP is $0.36 \mu \mathrm{g} / \mathrm{kg}-\mathrm{bw} / \mathrm{d}$. This value is higher than the previously obtained for beverages in China $(0.01 \mu \mathrm{g} / \mathrm{kg}-\mathrm{bw} / \mathrm{d})$ [40] and Europe $(0.00 \mu \mathrm{g} / \mathrm{kg}-\mathrm{bw} / \mathrm{d})$ [44]. Although human exposure to DMP from foods is limited 
$(\approx 10 \%)[40$ ] its assessment is important since it is an additional source of this low molecular weight PAE to the major one (cosmetics and personal care products) [44].

\section{Materials and Methods}

\subsection{Chemicals and Materials}

Analytical standards and solvents were used as received, without further purification. Acetonitrile (ACN, hypergrade for LC-MS) and hydrochloric acid $(25 \%, w / w)$ were bought from Merck (Darmstadt, Germany). Formic acid (for LC-MS) was acquired from Honeywell (Morris Plains, NJ, USA). Sodium hydroxide ( $\geq 98 \%)$, Th $(\geq 98.5 \%)$ and OctA $(>98 \%)$ were purchased from Sigma-Aldrich Chemie (Madrid, Spain). A Milli-Q A10 gradient system from Millipore (Bedford, MA, USA) was employed to obtain Milli-Q water.

Powdered standards of BBP (CAS 85-68-7), DBEP (CAS 117-83-9), DEHA (CAS 103-

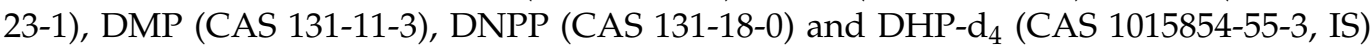
were acquired from Dr. Ehrenstorfer GmbH (Augsburg, Germany) with a purity of 97\% or higher. Standards (purity $\geq 97 \%$ ) of DBP (CAS 84-74-2), DCHP (CAS 84-61-7), DEHP (CAS 117-81-7), DEP (CAS 84-66-2), DMEP (CAS 117-82-8), DNOP (CAS 117-84-0), DPP (CAS 131-16-8) and dibutyl phthalate-3,4,5,6-d (DBP-d $_{4}$, CAS 93952-11-5, IS) were provided by Sigma-Aldrich (Madrid, Spain). Appropriate amounts of these compounds were weighed and dissolved in ACN to prepare stock solutions at concentrations in the range between 500 and $1000 \mathrm{mg} / \mathrm{L}$ and stored at $-18^{\circ} \mathrm{C}$. Working standard mixtures of these solutions were prepared by a combination of stock solutions.

The volumetric material was cleaned with soap and tap water, immersed in Nochromix ${ }^{\circledR}$ oxidizing agent (Godax Laboratories, Cabin John, MD, USA) and rinsed repeatedly with tap and Milli-Q water. The non-volumetric glassware was also cleaned with soap and tap water, rinsed with Milli-Q water and finally pyrolyzed at $550{ }^{\circ} \mathrm{C}$ for $4 \mathrm{~h}$. PAEs-free gloves from VWR and pipette tips from Gilson were employed in this work.

\subsection{Apparatus and Software}

Chromatographic separation and determination were performed using an Acquity H-Class ultra-performance liquid chromatography $\left(\mathrm{UPLC}^{\circledR}\right)$ system from Waters (Milford, MA, USA) coupled to an Acquity QDa Q MS (Waters Chromatography, Milford, MA, USA) through electrospray ionization (ESI). This system consisted of a quaternary solvent manager, an automatic sample manager with a flow-through needle and a column oven. The separation was carried out according to the method previously described by SantanaMayor et al. [25]. Gradient program was applied as follows: $0.0 \mathrm{~min} 50 / 50(v / v) \mathrm{A} / \mathrm{B}$, $4.0 \min 30 / 70(v / v) \mathrm{A} / \mathrm{B}, 7.0 \mathrm{~min} 0 / 100(v / v) \mathrm{A} / \mathrm{B}, 8.0 \mathrm{~min}$ 0/100 (v/v) A/B, $9.0 \mathrm{~min}$ $50 / 50(v / v) \mathrm{A} / \mathrm{B}, 11.0 \mathrm{~min} 50 / 50(v / v) \mathrm{A} / \mathrm{B}$. Column temperature, mobile phase flow and sample temperature were adjusted to $40{ }^{\circ} \mathrm{C}, 0.3 \mathrm{~mL} / \mathrm{min}$ and $10{ }^{\circ} \mathrm{C}$ respectively. The injection volume used was $2.5 \mu \mathrm{L}$. The $\mathrm{Q}$ was operated in SIM mode with positive ionization. Individual compounds were identified according to their specific ions and retention times (Table 4). Optimal cone voltages are also shown in Table 4. ESI capillary voltage and desolvation temperature were established at $1.5 \mathrm{kV}$ and $600{ }^{\circ} \mathrm{C}$.

For confirmatory purposes, a similar Acquity H-Class UPLC system coupled to a Xevo TDQ triple quadrupole (QqQ) MS through ESI was employed. Separation conditions were as reported in [9]. The mobile phase was pumped at $0.3 \mathrm{~mL} / \mathrm{min}$ and $40{ }^{\circ} \mathrm{C}$ under the following program: $0.0 \mathrm{~min} 20 / 80(v / v) \mathrm{A} / \mathrm{B}, 1.0 \mathrm{~min} 0 / 100(v / v) \mathrm{A} / \mathrm{B}, 2.0 \mathrm{~min} 0 / 100(v / v)$ $\mathrm{A} / \mathrm{B}, 3.0 \mathrm{~min} 20 / 80(v / v) \mathrm{A} / \mathrm{B}, 5.0 \mathrm{~min} 20 / 80(v / v) \mathrm{A} / \mathrm{B}$. In this case, $5.0 \mu \mathrm{L}$ of samples or standards were injected (at $10^{\circ} \mathrm{C}$ ). The QqQ was operated in multiple reaction monitoring (MRM) mode and positive ionization. Two transitions were monitored (Table 4) and a maximum tolerance of $\pm 20 \%$ was set for the relative intensities of precursor and product ions [45]. The rest of the parameters for the MS were set as follows: capillary voltage, $3.5 \mathrm{kV}$, desolvation temperature, $500{ }^{\circ} \mathrm{C}$; source temperature, $150{ }^{\circ} \mathrm{C}$, desolvation gas flow $\left(\mathrm{N}_{2}\right)$, $900 \mathrm{~L} / \mathrm{h}$, cone gas flow $\left(\mathrm{N}_{2}\right), 50 \mathrm{~L} / \mathrm{h}$; collision gas pressure $(\mathrm{Ar}), 0.5$ bar. 
Table 4. MS and MS/MS parameters of the selected plasticizers and ISs.

\begin{tabular}{|c|c|c|c|c|c|c|c|c|c|c|}
\hline \multirow[b]{2}{*}{ Analyte } & \multicolumn{3}{|c|}{ SIM } & \multicolumn{7}{|c|}{ MRM } \\
\hline & $\begin{array}{l}\mathrm{Rt} \\
(\mathrm{min})\end{array}$ & $\begin{array}{l}\text { Ion } \\
(\mathrm{m} / \mathrm{z})\end{array}$ & $\begin{array}{c}\text { Cone } \\
\text { Voltage (V) }\end{array}$ & Rt (min) & $\begin{array}{l}\text { Quantification } \\
\text { Transition }(\mathrm{m} / \mathrm{z})\end{array}$ & $\begin{array}{c}\text { Cone } \\
\text { Voltage (V) }\end{array}$ & $\begin{array}{l}\text { Collision } \\
\text { Energy (V) }\end{array}$ & $\begin{array}{c}\text { Qualification } \\
\text { Transition }(\mathrm{m} / \mathbf{z})\end{array}$ & $\begin{array}{c}\text { Cone } \\
\text { Voltage (V) }\end{array}$ & $\begin{array}{l}\text { Collision } \\
\text { Energy (V) }\end{array}$ \\
\hline DMP & 0.79 & 162.9 & 16 & 0.56 & $195.0 \rightarrow 76.9$ & 16 & 32 & $195.0 \rightarrow 162.9$ & 16 & 8 \\
\hline DMEP & 0.81 & 283.1 & 14 & 0.55 & $283.1 \rightarrow 58.9$ & 14 & 16 & $283.1 \rightarrow 207.0$ & 14 & 6 \\
\hline DEP & 1.30 & 176.9 & 16 & 0.63 & $223.1 \rightarrow 148.9$ & 16 & 18 & $223.1 \rightarrow 176.9$ & 16 & 8 \\
\hline DPP & 2.45 & 148.9 & 18 & 0.76 & $251.1 \rightarrow 148.9$ & 18 & 16 & $251.1 \rightarrow 191.0$ & 18 & 6 \\
\hline BBP & 3.84 & 205.0 & 22 & 0.93 & $313.4 \rightarrow 90.9$ & 22 & 16 & $313.4 \rightarrow 205.0$ & 22 & 8 \\
\hline DBP & 4.09 & 279.1 & 14 & 1.03 & $279.1 \rightarrow 148.9$ & 14 & 12 & $279.1 \rightarrow 205.0$ & 14 & 6 \\
\hline DBEP & 4.18 & 367.2 & 18 & 1.01 & $367.2 \rightarrow 44.9$ & 18 & 24 & $367.2 \rightarrow 54.6$ & 18 & 16 \\
\hline DNPP & 5.67 & 148.9 & 22 & 1.50 & $307.2 \rightarrow 148.9$ & 22 & 14 & $307.2 \rightarrow 219.0$ & 22 & 8 \\
\hline DEHP & 5.72 & 166.9 & 22 & 2.91 & $391.3 \rightarrow 113.0$ & 22 & 8 & $391.3 \rightarrow 166.9$ & 22 & 12 \\
\hline DCHP & 5.78 & 331.2 & 22 & 1.60 & $331.2 \rightarrow 148.9$ & 22 & 26 & $331.2 \rightarrow 166.9$ & 22 & 12 \\
\hline DEHA & 8.20 & 129.0 & 24 & 2.93 & $371.4 \rightarrow 110.9$ & 24 & 24 & $371.4 \rightarrow 129.0$ & 24 & 16 \\
\hline DNOP & 8.35 & 148.9 & 22 & 3.04 & $391.4 \rightarrow 92.9$ & 22 & 58 & $391.4 \rightarrow 148.9$ & 22 & 22 \\
\hline DBP-d $\mathrm{d}_{4}$ & 3.96 & 153.0 & 20 & 1.03 & $283.2 \rightarrow 153.0$ & 20 & 12 & $283.2 \rightarrow 209.0$ & 20 & 8 \\
\hline DHP-d 4 & 6.84 & 237.1 & 22 & 2.11 & $339.3 \rightarrow 153.0$ & 22 & 12 & $339.3 \rightarrow 237.1$ & 22 & 8 \\
\hline
\end{tabular}

In both instruments, water and $\mathrm{ACN}$ with $0.1 \% v / v$ formic acid were used as aqueous (A) and organic (B) mobile phases, respectively. The same column (Acquity UPLC ${ }^{\circledR}$ BEH C $_{18}, 50 \mathrm{~mm} \times 2.1 \mathrm{~mm}, 1.7 \mu \mathrm{m}$, Waters) and pre-column (Acquity UPLC ${ }^{\circledR}$ BEH C $_{18}$, $5 \mathrm{~mm} \times 2.1 \mathrm{~mm}, 1.7 \mu \mathrm{m}$, Waters) were also employed in both instruments. MassLynx software (Waters Chromatography) was used to control the instruments (pumps, sample manager and MS parameters), data acquisition and processing.

\subsection{NaHDES Synthesis and VA-LLME}

The synthesis of the NaHDESs used in the subsequent LLME protocol was made according to our previous experience [8,9]. Suitable amounts (molar ratio 2:1) of Th and OctA were mixed in screw-capped glass tubes and heated $\left(80^{\circ} \mathrm{C}\right)$ and stirred $(850 \mathrm{rpm})$ for $10 \mathrm{~min}$. As a result, homogeneous transparent DES liquids were obtained. For VA-LLME, $125 \mu \mathrm{L}$ of the NaHDES were rapidly injected into $10 \mathrm{~mL}$ of kombucha, previously adjusted to $\mathrm{pH} 6.00$ (with $\mathrm{NaOH} 0.1 \mathrm{M}$ or $6 \mathrm{M}$ or $\mathrm{HCl} 0.1 \mathrm{M}$ solutions) and spiked with ISs (at $25 \mu \mathrm{g} / \mathrm{L}$ ). After vortexing for $1 \mathrm{~min}$, the mixture was centrifuged (3000 rpm $-2465 \times \mathrm{g}$ $10 \mathrm{~min}, 15^{\circ} \mathrm{C}$ ) in an Eppendorf 5810R centrifuge (Hamburg, Germany). Ten $\mu \mathrm{L}$ of the floating drop were recovered and diluted 20-fold with ACN for injection.

\subsection{Samples Slection}

A total of 26 different varieties of kombucha from nine different brands (Table S1) were purchased in supermarkets and/or organic shops from Tenerife (Canary Islands, Spain). These samples had the EU organic product label and were bottled in glass containers with plastic caps (19) or in plastic bottles (7). The samples had different fruity (K5, K7, K8, $\mathrm{K} 10-\mathrm{K} 13, \mathrm{~K} 15-\mathrm{K} 18, \mathrm{~K} 20-\mathrm{K} 24$ and K26) and herbal (K3, K4, K14) flavors. Among them, two varieties are declared as zero sugar (manufacturer indicates on the label that the sugar is fully consumed during fermentation). It should be noted that one variant (K19) contained an algae (spirulina) among its ingredients.

The $\mathrm{pH}$ of the original samples varied between 2.80 and 3.25, as expected for acidic beverages. The nutritional information $(\mathrm{g} / 100 \mathrm{~g}$, according to their labels) indicated that carbohydrates varied between 0.0 and 4.5 , fats ranged between 0.0 and 0.5 and proteins oscillated in the range $0.0-0.7$.

A plain kombucha (without additional flavors) was selected to validate the methodology. For this purpose, that sample was analyzed to check for PAEs content and no residues were detected. In order to separate SCOBY from the liquid phase, the samples were cen- 
trifuged (3400 rpm — 2326 $\times g$ - for $10 \mathrm{~min}$ ) and filtered (0.45 $\mu \mathrm{m}$ filters PVDF, Millipore, Sigma-Aldrich). Finally, the samples were degassed (magnetic stirring for $10 \mathrm{~min}$ ) before $\mathrm{pH}$ adjustment. It should be noted that the sample portion considered for analysis was selected on the basis of the end-user's consumption pattern. Kombucha producers separate the SCOBY from the liquor before bottling it [12], thus a reduced sedimented phase is incorporated in the commercial format (e.g. $0.0413 \pm 0.011 \% w / v$ for the kombucha used during validation).

\section{Conclusions}

A VA-LLME-UHPLC-MS method [9] based on the NaHDES Th:OctA molar ratio 2:1 has been used for the analysis of a group of 11 PAEs (DMP, DMEP, DEP, DPP, BBP, DBP, DBEP, DNPP, DCHP, DEHP and DNOP) and one adipate (DEHA) in 26 varieties of kombuchas (19 samples bottled in glass and 7 samples bottled in plastic). Among these samples, different varieties with fruity and/or herbal flavors were included. Only DMP and DBP were detected in 11 samples, although frequently at concentrations lower than the LOQ. Almost all the kombuchas bottled in plastic present these PAEs. However, despite being only present in five of the 19 samples in glass bottles, the highest concentration was detected for DMP $(16.18 \pm 1.14 \mu \mathrm{g} / \mathrm{L})$ in one of these matrices. Although this aspect was certainly contrary to what was expected (higher concentration of phthalates in plasticbottled samples), only $26 \%$ of the samples bottled in glass presented PAEs vs. $85 \%$ of the analyzed samples packaged in plastic. The presence of these compounds in samples bottled in glass could be due to the plastic materials in the manufacturing line or because of the caps in contact with the kombuchas (acidic beverages facilitate the migration of DMP and DBP). These results show the need to assess foods/drinks in which these substances are not expected to be found. It should be mentioned that the estimated daily intake for DMP in kombucha $(0.36 \mu \mathrm{g} / \mathrm{kg}$-bw $/ \mathrm{d})$ was higher than the obtained for beverages in China $(0.01 \mu \mathrm{g} / \mathrm{kg}-\mathrm{bw} / \mathrm{d})$ and Europe $(0.00 \mu \mathrm{g} / \mathrm{kg}-\mathrm{bw} / \mathrm{d})$. Finally, it should be remarked that the method employed is green (use of small volumes of a natural and sustainable solvent), quick, easy, and provides good extraction efficiency. To our knowledge, this paper reports for the first time the analysis of these plastic migrants in kombucha.

Supplementary Materials: The following supporting information can be downloaded. Table S1: Characteristics of the analyzed samples.

Author Contributions: Conceptualization, A.V.H.-H. and M.Á.R.-D.; methodology, A.V.H.-H., R.R.R., Á.S.-M., B.S.-R.; validation, A.V.H.-H., R.R.-R.; formal analysis, A.V.H.-H.; investigation, A.V.H.-H., R.R.-R., Á.S.-M., B.S.-R., M.Á.R.-D.; resources, M.Á.R.-D.; writing—original draft preparation, A.V.H.H.; writing—review and editing, A.V.H.-H., B.S.-R., M.Á.R.-D.; supervision, M.Á.R.-D.; project administration, M.Á.R.-D.; funding acquisition, M.Á.R.-D. All authors have read and agreed to the published version of the manuscript.

Funding: This research was funded by the Spanish Ministry of Economy, Industry and Competitiveness (project AGL2017-89257-P). R.R.-R. and Á.S.-M. would like to thank the Canary Agency of Economy, Industry, Trade and Knowledge of the Government of the Canary Islands for the FPI fellowship (co-financed from Agencia Canaria de Investigación, Innovación y Sociedad de la Información de la Consejería de Economía, Conocimiento y Empleo y por el Fondo Social Europeo (FSE) Programa Operativo Integrado de Canarias 2014-2020, Eje 3 Tema Prioritario 74 (85\%)).

Institutional Review Board Statement: Not applicable.

Informed Consent Statement: Not applicable.

Data Availability Statement: Data supporting reported results are included in this document.

Acknowledgments: Authors would like to acknowledge the use of the Research Support General Service (SEGAI) of the University of La Laguna.

Conflicts of Interest: The authors declare no conflict of interest. 


\section{References}

1. US Environmental Protection Agency. Basics of Green Chemistry. Available online: https://www.epa.gov/greenchemistry/ basics-green-chemistry (accessed on 14 November 2021).

2. Pena-Pereira, F.; Kloskowski, A.; Namieśnik, J. Perspectives on the replacement of harmful organic solvents in analytical methodologies: A framework toward the implementation of a generation of eco-friendly alternatives. Green Chem. 2015, 17, 3687-3705. [CrossRef]

3. Durand, E.; Lecomte, J.; Villeneuve, P. From green chemistry to nature: The versatile role of low transition temperature mixtures. Biochimie 2016, 120, 119-123. [CrossRef]

4. Socas-Rodríguez, B.; Santana-Mayor, Á.; Herrera-Herrera, A.V.; Rodríguez-Delgado, M.Á. Deep Eutectic Solvents. In Green Sustainable Process for Chemical and Environmental Engineering and Science; Inamuddin, Asiri, A.M., Kanchi, S., Eds.; Elsevier: Amsterdam, The Netherlands, 2019; pp. 123-177.

5. Santana-Mayor, Á.; Rodríguez-Ramos, R.; Herrera-Herrera, A.V.; Socas-Rodríguez, B.; Rodríguez-Delgado, M.Á. Deep eutectic solvents. The new generation of green solvents in analytical chemistry. TrAC Trends Anal. Chem. 2021, 134, 116108. [CrossRef]

6. Isci, A.; Kaltschmitt, M. Recovery and recycling of deep eutectic solvents in biomass conversions: A review. Biomass Convers. Biorefinery 2021. [CrossRef]

7. Makoś, P.; Słupek, E.; Gębicki, J. Hydrophobic deep eutectic solvents in microextraction techniques-A review. Microchem. J. 2020, 152, 104384. [CrossRef]

8. Santana-Mayor, Á.; Socas-Rodríguez, B.; Rodríguez-Ramos, R.; Herrera-Herrera, A.V.; Rodríguez-Delgado, M.Á. Quality assessment of environmental water by a simple and fast non-ionic hydrophobic natural deep eutectic solvent-based extraction procedure combined with liquid chromatography tandem mass spectrometry for the determination of plastic migrants. Anal. Bioanal. Chem. 2021, 413, 1967-1981. [CrossRef] [PubMed]

9. Santana-Mayor, Á.; Herrera-Herrera, A.V.; Rodríguez-Ramos, R.; Socas-Rodríguez, B.; Rodríguez-Delgado, M.Á. Development of a green alternative vortex-assisted dispersive liquid-liquid microextraction based on natural hydrophobic deep eutectic solvents for the analysis of phthalate esters in soft drinks. ACS Sustain. Chem. Eng. 2021, 9, 2161-2170. [CrossRef]

10. Hayyan, M.; Hashim, M.A.; Hayyan, A.; Al-Saadi, M.A.; AlNashef, I.M.; Mirghani, M.E.S.; Saheed, O.K. Are deep eutectic solvents benign or toxic? Chemosphere 2013, 90, 2193-2195. [CrossRef]

11. Hayyan, M.; Hashim, M.A.; Al-Saadi, M.A.; Hayyan, A.; AlNashef, I.M.; Mirghani, M.E.S. Assessment of cytotoxicity and toxicity for phosphonium-based deep eutectic solvents. Chemosphere 2013, 93, 455-459. [CrossRef]

12. Dutta, H.; Paul, S.K. Kombucha Drink: Production, Quality, and Safety Aspects. In Production and Management of Beverages. Volume 1: The Science of Beverages; Grumezescu, A.M., Holban, A.M., Eds.; Woodhead Publishing: Cambridge, UK, 2019 ; pp. $259-288$.

13. Soares, M.G.; de Lima, M.; Reolon Schmidt, V.C. Technological aspects of kombucha, its applications and the symbiotic culture (SCOBY), and extraction of compounds of interest: A literature review. Trends Food Sci. Technol. 2021, 110, 539-550. [CrossRef]

14. Ahuja, K.; Singh, S. Kombucha Market Size, by Product (Organic and Inorganic), By Type (Original and Flavored $\{$ Herbs \& Spices, Fruits, Flowers and Others\}), By Distribution Channel (Supermarkets/Hypermarkets, Convenience Stores, Health Stores, Online Retailers and Others). Available online: https://www.marketresearch.com/One-Off-Global-Market-Insights-v4130/KombuchaSize-Product-Organic-Inorganic-14738792/ (accessed on 14 November 2021).

15. Wang, Y.; Zhu, H.; Kannan, K. A review of biomonitoring of phthalate exposures. Toxics 2019, 7, 21. [CrossRef] [PubMed]

16. Yang, J.; Li, Y.; Wang, Y.; Ruan, J.; Zhang, J.; Sun, C. Recent advances in analysis of phthalate esters in foods. TrAC Trends Anal. Chem. 2015, 72, 10-26. [CrossRef]

17. Center for Disease Control and Prevention. National Report on Human Exposure to Environmental Chemicals. Available online: https:/ / www.cdc.gov / exposurereport/ (accessed on 14 November 2021).

18. Sero, R.; Nunez, O.; Santos, F.J.; Moyano, E. Analytical Methods for the Determination of Plasticizers in Food and Beverages. Curr. Anal. Chem. 2018, 14, 306-324. [CrossRef]

19. Santana-Mayor, Á.; Socas-Rodríguez, B.; Rodríguez-Ramos, R.; Rodríguez-Delgado, M.Á. A green and simple procedure based on deep eutectic solvents for the extraction of phthalates from beverages. Food Chem. 2020, 312, 125798. [CrossRef]

20. Wang, X.; Lu, Y.; Shi, L.; Yang, D.; Yang, Y. Novel low viscous hydrophobic deep eutectic solvents liquid-liquid microextraction combined with acid base induction for the determination of phthalate esters in the packed milk samples. Microchem. J. 2020, 159, 105332. [CrossRef]

21. Ortega-Zamora, C.; González-Sálamo, J.; Hernández-Sánchez, C.; Hernández-Borges, J. Menthol-Based Deep Eutectic Solvent Dispersive Liquid-Liquid Microextraction: A Simple and Quick Approach for the Analysis of Phthalic Acid Esters from Water and Beverage Samples. ACS Sustain. Chem. Eng. 2020, 8, 8783-8794. [CrossRef]

22. Gałuszka, A.; Migaszewski, Z.M.; Konieczka, P.; Namieśnik, J. Analytical Eco-Scale for assessing the greenness of analytical procedures. TrAC Trends Anal. Chem. 2012, 37, 61-72. [CrossRef]

23. European Union. Commission Regulation (EU) No 10/2011 of 14 January 2011 on plastic materials and articles intended to come into contact with food. Off. J. Eur. Union 2011, L12, 1-89.

24. EPA Phthalates Action Plan-U.S. Environmental Protection Agency. Available online: https://www.epa.gov/sites/production/ files/2015-09/documents/phthalates_actionplan_revised_2012-03-14.pdf (accessed on 14 November 2021). 
25. Santana-Mayor, Á.; Socas-Rodríguez, B.; Afonso, M.M.; Palenzuela-López, J.A.; Rodríguez-Delgado, M.Á. Reduced graphene oxide-coated magnetic-nanoparticles as sorbent for the determination of phthalates in environmental samples by micro-dispersive solid-phase extraction followed by ultra-high-performance liquid chromatography tandem mass spectrometry. J. Chromatogr. A 2018, 1565, 36-47. [CrossRef]

26. Guo, Y.; Kannan, K. Challenges encountered in the analysis of phthalate esters in foodstuffs and other biological matrices. Anal. Bioanal. Chem. 2012, 404, 2539-2554. [CrossRef]

27. Martins, M.A.R.; Crespo, E.A.; Pontes, P.V.A.; Silva, L.P.; Bülow, M.; Maximo, G.J.; Batista, E.A.C.; Held, C.; Pinho, S.P.; Coutinho, J.A.P. Tunable Hydrophobic Eutectic Solvents Based on Terpenes and Monocarboxylic Acids. ACS Sustain. Chem. Eng. 2018, 6, 8836-8846. [CrossRef]

28. Bezold, F.; Minceva, M. Liquid-liquid equilibria of n-heptane, methanol and deep eutectic solvents composed of carboxylic acid and monocyclic terpenes. Fluid Phase Equilib. 2018, 477, 98-106. [CrossRef]

29. Cortese, M.; Gigliobianco, M.R.; Magnoni, F.; Censi, R.; Di Martino, P. Compensate for or minimize matrix effects? strategies for overcoming matrix effects in liquid chromatography-mass spectrometry technique: A tutorial review. Molecules 2020, $25,3047$. [CrossRef]

30. Matuszewski, B.K.; Constanzer, M.L.; Chavez-Eng, C.M. Strategies for the assessment of matrix effect in quantitative bioanalytical methods based on HPLC-MS/MS. Anal. Chem. 2003, 75, 3019-3030. [CrossRef] [PubMed]

31. Andrade, J.M.; Gómez-Carracedo, M.P. Notes on the use of Mandel's test to check for nonlinearity in laboratory calibrations. Anal. Methods 2013, 5, 1145-1149. [CrossRef]

32. ISO 8466-2:2001. Water Quality-Calibration and Evaluation of Analytical Methods and Estimation of Performance Characteristics-Part 2: Calibration Strategy for Non-Linear Second-Order Calibration Functions. International Organization for Standardization: Geneva, Switzerland. 2001. Available online: https:/ /www.iso.org/standard/34816.html (accessed on 14 November 2021).

33. Bošnir, J.; Puntarić, D.; Galić, A.; Škes, I.; Dijanić, T.; Klarić, M.; Grgić, M.; Čurković, M.; Šmit, Z. Migration of phthalates from plastic containers into soft drinks and mineral water. Food Technol. Biotechnol. 2007, 45, 91-95.

34. US Environmental Protection Agency (US EPA). 40 CFR 141-National Primary Drinking Water Regulations: Maximum Contaminant Levels and Maximum Residual Disinfectant. In Code of Federal Regulations (annual edition) Levels; US EPA: Washington, DC, USA, 2019. Available online: https:/ /www.epa.gov/sites/default/files/2019-03/documents/cfr-2011-title40-vol23-part141.pdf (accessed on 14 November 2021).

35. World Health Organization. Guidelines for Drinking-Water Quality, 4th ed.; World Health Organization: Geneva, Switzerland, 2011.

36. Been, F.; Malarvannan, G.; Bastiaensen, M.; Yin, S.; van Nuijs, A.L.N.; Covaci, A. Development and validation of a bioanalytical assay based on liquid chromatography-tandem mass spectrometry for measuring biomarkers of exposure of alternative plasticizers in human urine and serum. Talanta 2019, 198, 230-236. [CrossRef]

37. Van Vliet, E.D.S.; Reitano, E.M.; Chhabra, J.S.; Bergen, G.P.; Whyatt, R.M. A review of alternatives to di (2-ethylhexyl) phthalatecontaining medical devices in the neonatal intensive care unit. J. Perinatol. 2011, 31, 551-560. [CrossRef]

38. Wu, P.-G.; Pan, X.-D.; Ma, B.-J.; Wang, L.-Y.; Zhang, J. Determination of phthalate esters in non-alcoholic beverages by GC-MS and optimization of the extraction conditions. Eur. Food Res. Technol. 2014, 238, 607-612. [CrossRef]

39. Xue, X.; Su, Y.; Su, H.; Fan, D.; Jia, H.; Chu, X.; Song, X.; Liu, Y.; Li, F.; Xue, J.; et al. Occurrence of Phthalates in Bottled Drinks in the Chinese Market and Its Implications for Dietary Exposure. Molecules 2021, 26, 6054. [CrossRef]

40. Guo, Y.; Zhang, Z.; Liu, L.; Li, Y.; Ren, N.; Kannan, K. Occurrence and Profiles of Phthalates in Foodstuffs from China and Their Implications for Human Exposure. J. Agric. Food Chem. 2012, 60, 6913-6919. [CrossRef]

41. EFSA Panel on Dietetic Products, Nutrition, and Allergies (NDA). Scientific Opinion on Dietary Reference Values for Water. EFSA J. 2016, 8, 1459. [CrossRef]

42. Grandjean, A.C. Water requirements, impinging factors and recommended intakes. In Nutrients in Drinking Water; World Health Organization, Ed.; World Health Organization: Geneva, Switzerland, 2004; pp. 25-40.

43. Walpole, S.C.; Prieto-Merino, D.; Edwards, P.; Cleland, J.; Stevens, G.; Roberts, I. The weight of nations: An estimation of adult human biomass. BMC Public Health 2012, 12, 439. [CrossRef]

44. Wormuth, M.; Scheringer, M.; Vollenweider, M.; Hungerbühler, K. What Are the Sources of Exposure to Eight Frequently Used Phthalic Acid Esters in Europeans? Risk Anal. 2006, 26, 803-824. [CrossRef]

45. European Commission. COMMISSION DECISION of 12 August 2002 implementing Council Directive 96/23/EC concerning the performance of analytical methods and the interpretation of results (2002/657/EC). Off. J. Eur. Communities 2002, L 221/8-L 221/36. 